\title{
Contrast Induced Nephropathy and Gender Variation
}

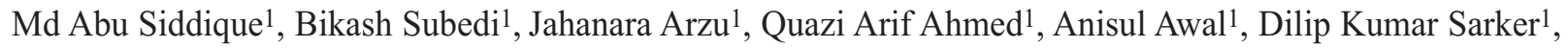 \\ Md Sirajul Islam¹, Md Mukhlesur Rahman ${ }^{1}$, Md Khursed Ahmed ${ }^{1}$, Nilufar Fatema1, Md Ashraf Uddin Sultan ${ }^{1}$ \\ S. M. Mustafa Zaman ${ }^{1}$, Md. Harisul Hoque ${ }^{1}$ \\ 1 Department of Cardiology, Bangabandhu Sheikh Mujib Medical University, Dhaka
}

Address for Correspondance

Professor Dr. Md. Abu Siddique, Department of Cardiology

Bangabandhu Sheikh Mujib Medical University, Dhaka

e - mail : drabusiddique@yahoo.com

\begin{abstract}
Contrast-induced nephropathy (CIN) is a recognized complication after percutaneous interventions (PCI). We sought to determine the impact of gender on incidence of CIN. Of a total 200 patients who underwent PCI, there were 33 (16.5\%) who developed CIN (defined as $>25 \%$ rise in creatinine after PCI). CIN was present in $23.6 \%$ of female versus $17.4 \%$ of male patients $(\mathrm{p}<0.0001)$. Multivariate analysis showed that female gender $(\mathrm{p}<0.0001)$, pre-PCI chronic renal failure $(\mathrm{CRF})(\mathrm{OR}=1.8,95 \%$ $\left.\mathrm{CI}=1.53 \mathrm{a} €^{\prime \prime} 2.10, \mathrm{p}<0.0001\right)$, diabetes mellitus $(\mathrm{OR}=1.5,95 \%, \mathrm{p}<0.0001)$, age $(\mathrm{OR}=1.01, \mathrm{p}<0.0001)$, and hypertension $(\mathrm{OR}=1.2, \mathrm{p}=0.0035)$ were independent predictors of $\mathrm{CIN}$. By multivariate analysis only baseline CRF, diabetes, age, functional NYHA IV class were identified as independent risk factor for CIN. Female gender is an independent predictor of CIN development.
\end{abstract}

Key words : Contrast-induced nephropathy, Percutaneous interventions, Serum Creatinine.

\section{Introduction}

Since their introduction in the 1950 s, organic radiographic iodinated contrast media (ICM) have been among the most commonly prescribed drugs in the history of modern medicine. The phenomenon of present-day radiologic imaging would be lacking without these agents. ICM generally have a good safety record. Adverse effects from the intravascular administration of ICM are generally mild and self-limited; reactions that occur from the extravascular use of ICM are rare. ${ }^{1}$ CIN has become a topic of interest due to a marked increase in the number of diagnostic and interventional radiological imaging procedures. The topic is of special significance to the cardiologist due to number of reasons. Firstly, patients undergoing coronary angiography have often associated risk factors for developing contrast induced nephropathy, such as diabetes, congestive heart failure and pre existing renal impairment. Secondly, contrast load is high during PCI and often exceeds $100 \mathrm{ml}$, the usual safety limit for avoiding CIN. Thirdly, long term outcome after PCI is significantly worse in patients who develop CIN. Finally few prophylactic approaches have recently been found to be effective against CIN.

Contrast-induced nephropathy (CIN) may occur after percutaneous coronary interventions (PCI), particularly in patients with baseline chronic renal failure (CRF) and diabetes. We have reported on the adverse impact of CIN post-PCI in patients with CRF (creatinine rise of at least 25\% from baseline within 48 hours after PCI. In this study, we analyzed the impact of gender on development of CIN .

\section{Methods}

Patient population

From a total of 200 consecutive patients undergoing PCI between January 2007 to December 2008 in Bangabandhu Sheikh Mujib Medical University, Dhaka, we identified 33 patients $(16.5 \%)$ who developed CIN, defined as $>25 \%$ rise in serum creatinine value compared to baseline serum creatinine level.

\section{Procedures}

All patients underwent cardiac catheterization and PCI by standard techniques using the femoral approach.With informed consent, intervention cardiologist selected the devices and procedures at their discretion. All patients received ionic low-osmolar contrast agents; in particular. Patients with $\mathrm{CRF}$ received intravenous hydration with half normal saline at $60 \mathrm{ml} /$ hours for 12 hours before the procedure and for 12 hours after the procedure.

Table I. Distribution of patients by baseline characteristics

\begin{tabular}{|c|c|c|c|}
\hline \multirow[b]{2}{*}{ Baseline eharacteristics } & \multicolumn{2}{|c|}{ Group } & \multirow[b]{2}{*}{$\begin{array}{c}\text { p- } \\
\text { value }\end{array}$} \\
\hline & $\begin{array}{c}\text { female } \\
(n-120)\end{array}$ & $\underset{(\mathrm{n}-\mathbf{8 D})}{\text { male }}$ & \\
\hline Serum creatinine concentration ${ }^{*}$ & $1.4 \pm 1.3$ & $0.9 \pm 0.2$ & 0.001 \\
\hline Pre-prosedural CRF & 3.236 & $2.9 \%$ & 40.001 \\
\hline Systolic blood pressurc* & $139.3 \pm 23.2$ & $130.9 \pm 19.7$ & 0.068 \\
\hline Redaced LVEF $(<5036)^{\prime}$ & $39(32.5)$ & $7(8.8)$ & $\$ 0.001$ \\
\hline FBS* & $7,7 \pm 0.9$ & $5.8 \pm 5.0$ & $<0.001$ \\
\hline
\end{tabular}

\# Data were analysed using $\chi^{2}$ Test; *Student's t-Test was employed to analyse data. 
Table II. Distribution of patients by predisposing factors

\begin{tabular}{|l|c|c|c|}
\hline \multirow{2}{*}{ Factors } & \multicolumn{2}{|c|}{ Group } & \multirow{2}{*}{} \\
\cline { 2 - 3 } & $\begin{array}{c}\text { male } \\
(\mathrm{n}=\mathrm{80})\end{array}$ & $\begin{array}{c}\text { female } \\
(\mathrm{n}=120)\end{array}$ & \multirow{2}{*}{ p vulue } \\
\hline Hypurtension & $75(62.5)$ & $51(63.8)$ & 0.858 \\
\hline Dyslipidemih & $98(81.7)$ & $49(61.3)$ & 0.001 \\
\hline Smoking babit & $79(65.8)$ & $56(70.0)$ & 0.538 \\
\hline Previous MI & $69(57.8)$ & $31(38.8)$ & 0.009 \\
\hline Previous CABG & $2(1.7)$ & $1(1.3)$ & 0.649 \\
\hline
\end{tabular}

All the data expressed in number and percent

Table III. Association between gender and CIN

\begin{tabular}{|l|c|c|}
\hline & $\begin{array}{c}\text { CIN Developed } \\
(\mathrm{n}=33)\end{array}$ & p-value \\
\hline Female & $23.6 \%$ & \\
\hline male & $17.4 \%$ & $<0.05$ \\
\hline
\end{tabular}

Data expressed in percent

\section{Statistical analysis}

Statistical analysis was performed using SPSS 12.5 Continuous variables are expressed as mean $\mathrm{A} \pm$ standard deviation and categorical variables as number (\%). Continuous variables were estimated using analysis of variance (ANOVA) or Student's t-test. Categorical variables were compared with a chi-square or Fisher's exact test. A 'p' value $<0.05$ was considered significant.

\section{Results}

Of a total 200 patients who underwent PCI, there were 33 $(16.5 \%)$ who developed CIN. Baseline patient characteristics are shown in Table 1. CIN was present in $(23.6 \%)$ of female versus $17.4 \%$ male patients $(\mathrm{p}<0.0001)$. Pre-procedural CRF was present $3.2 \%$ female and $2.9 \%$ male patients. In patients without baseline CRF, females had higher rates of hypertension and diabetes $(\mathrm{p}<0.0001$ for both) and lower rates of previous bypass surgery $(\mathrm{p}=0.002)$ and as expected, smaller BSA $(\mathrm{p}<0.0001)$.

Multivariate analysis showed that female gender $(\mathrm{OR}=1.4$, $\mathrm{p}<0.0001)$, pre-PCI chronic renal failure $(\mathrm{CRF})(\mathrm{OR}=1.8, \mathrm{p}$ $<0.0001)$, diabetes mellitus ( $\mathrm{OR}=1.5,95 \% ; \mathrm{p}<0.0001)$, age $(\mathrm{OR}=1.01, \mathrm{p}<0.0001)$, and hypertension $(\mathrm{OR}=1.2, \mathrm{p}$ $=0.0035)$ were independent predictors of CIN.

\section{Discussion}

This study demonstrates CIN is frequent complication after coronary angiogram. In this study, we found that female gender is among the independent predictors of CIN after
Similar to other reports, ${ }^{11,12}$ our findings show that diabetes and CRF, along with hypertension and hypercholesterolemia are predisposing factors to CIN. Acute contrast-induced reductions in renal function among patients with diabetes have been reported to be $9-40 \%$ in patients with mild- to moderate chronic renal impairment and 5-90\% in patients with severe chronic renal failure. ${ }^{2-12}$ Also, we found that female gender is an independent risk factor for CIN. Gender specific response to renal stimuli as contrast agent may be a possible explanation. Several studies have demonstrated gender differences in platelet response and reactivity, including a greater sensitivity of the platelets of women to aggregating stimuli. ${ }^{13,14}$ Results from other studies suggest influence of ovarian hormones in the evolution of renal failure. ${ }^{15,16}$ Another possible explanation may be the discrepancy between the volume amount of contrast used and the body surface area. Women, in general have smaller BSA than men and the above mentioned gender effect could be a manifestation of women's smaller size. In our study, women without baseline CRF received smaller amount of contrast volume (even if corrected by the BSA) compared to men without CRF. 17,18

Study limitations: This study included a small number of population. It is single centered study and other pathologies of nephropathy could not be excluded.

\section{Conclusion}

Female gender is one of the important predictors of contrast induced nephropathy. However our finding has to be supported by other multicentered studies that which include a large number of populations.

\section{References}

1. American College of Radiology. Manual on Contrast Media. $4^{\text {th }}$ ed. Reston, Va: ACR; 1998

2. Gaca AM, Frush DP, Hohenhaus SM, et al. Enhancing pediatric safety: using simulation to assess radiology resident preparedness for anaphylaxis from intravenous contrast media. Radiology. 2007;245(1):236-44

3. Cutroneo P, Polimeni G, Curcuruto R, Calapai G, Caputi AP. Adverse reactions to contrast media: an analysis from spontaneous reporting data. Pharmacol Res. 2007;56(1):35-41

4. Solomoin R, Werner C, MannD, Silva P, Effect of saline, mannitol and furosemide to prevent acute decrease in renal function induced by radiocontrast agents. $N$ Engl J Med. 1994:331:1412-20

5. Bush WH, Swanson DP. Acute reactions to intravascular contrast media: types, risk factors, recognition, and specific treatment. Am J Roentgenol.1991;157(6):1153-61 
6. Becker C. [Prophylaxis and treatment of side effects due to iodinated contrast media relevant to radiological practice] [German]. Radiology. 2007;47(9):768-73

7. Dimari J,Megyesi J,Udvarhelyi N.N-Acetylcysteine amelioraters ischemic renal failure. Am J Physiol 1997:272:292-98

8. Lasser EC, Berry CC, Talner LB, et al. Pretreatment with corticosteroids to alleviate reactions to intravenous contrast material. N Engl J Med. 1987;317(14):845-49

9. Wolf GL, Arenson RL, Cross AP. A prospective trial of ionic vs nonionic contrast agents in routine clinical practice: comparison of adverse effects. Am J Roentgenol. 1989;152(5):939-44

10. Dillman JR, Strouse PJ, Ellis JH, Cohan RH, Jan SC. Incidence and severity of acute allergic-like reactions to i.v. nonionic iodinated contrast material in children. $\mathrm{Am} \mathrm{J}$ Roentgenol. 2007;188(6):1643-47

11. Caro JJ, Trindade E, McGregor M. The risks of death and of severe nonfatal reactions with high- vs low-osmolality contrast media: a meta-analysis. Am J Roentgenol. 1991; 156(4): 825-32

12. Kinnison ML, Powe NR, Steinberg EP. Results of randomized controlled trials of low-versus high-osmolality contrast media. Radiology. 1989;170 (2):381-89
13. Memolo M, Dyer R, Zagoria RJ. Extravasation injury with nonionic contrast material [letter]. Am J Roentgenol. 1993;160(1):203-04

14. Foord KD, Kaye B, Howard J, Cumberland DC. Comparison of the side-effects of low-osmolar contrast media in intravenous urography. Clin Radiol. 1985;36(4):379-80

15. Greenberger PA, Patterson R, Radin RC. Two pretreatment regimens for high-risk patients receiving radiographic contrast media. J Allergy Clin Immunol. 1984;74(4 pt 1):540-43

16. Tepel M, Zidek W. Acetylcysteine and contrast media nephropathy. Curr Opin Nephrol Hypertens. 2002; 11(5):503-06

17. Shehadi WH. Adverse reactions to intravascularly administered contrast media. A comprehensive study based on a prospective survey. Am J Roentgenol Radium Ther Nucl Med. 1975;124(1):145-52

18. Grudberg 1,Mintz GS,MehranR,et al.The prognostic implication of further renal function deterioration within 48 hours of interventional coronary proceduresin patients with pre-existantchronic renal insufficiency. $J \mathrm{Am}$ Coll Cardiol 2000;36;1542-48 